\title{
Zastosowanie elektromiografii w praktyce otolaryngologicznej i foniatrycznej
}

\section{Laryngeal electromyography in laryngologic and phoniatric practice}

\author{
Agata Szkiełkowska ${ }^{1,2}$, Paulina Krasnodębska ${ }^{1}$, Beata Miaśkiewicz ${ }^{1}$ \\ ${ }^{1}$ Instytut Fizjologii i Patologii Słuchu, Światowe Centrum Słuchu, Klinika Audiologii i Foniatrii, \\ Warszawa/Kajetany \\ ${ }^{2}$ Uniwersytet Muzyczny Fryderyka Chopina, Katedra Audiologii i Foniatrii, Warszawa
}

Adres autora: Paulina Krasnodębska, Światowe Centrum Słuchu, Klinika Audiologii i Foniatrii, ul. Mokra 17, Kajetany, 05-830 Nadarzyn, e-mail: p.krasnodebska@ifps.org.pl

\section{Streszczenie}

Współcześnie badanie elektromiograficzne jest złotym standardem diagnostycznym i prognostycznym w ocenie systemu nerwowo-mięśniowego. Wykorzystywane jest przede wszystkim w neurologii, do rozpoznawania chorób mięśni i nerwów obwodowych. Niniejszy artykuł ma na celu przegląd literatury światowej na temat współczesnego zastosowania badania elektromiograficznego w otolaryngologii i foniatrii.

Słowa kluczowe: elektromiografia • choroby krtani • zaburzenia głosu

Abstract

Electromyography is the gold standard of neuromuscular diagnostic and prognostic. It is used mainly in neurology, for diagnosing muscle and peripheral nerves diseases. This article aims to provide an overview of contemporary world literature regarding the use of electromyography in otolaryngology and phoniatry.

Key words: electromyography • laryngeal diseases • voice disorders

\begin{abstract}
Wstęp
Badanie elektromiograficzne (EMG) stanowi współcześnie złoty standard diagnostyczny i prognostyczny w ocenie systemu nerwowo-mięśniowego [1]. Wykorzystywane jest przede wszystkim w neurologii, do rozpoznawania chorób mięśni i nerwów obwodowych. Nie należy jednak zapominać o zastosowaniu EMG w diagnostyce narządu głosu i mowy. Badanie elektromiograficzne krtani (ang. laryngeal electromyography, LEMG) zostało po raz pierwszy opisane w 1944 roku [2]. Rok później zaprezentowano urządzenie do rejestracji potencjałów elektromiograficznych dla celów klinicznych, umożliwiając diagnostykę neurofizjologiczną mięśni krtani [3]. LEMG pozwala na przedstawienie aktywności elektrycznej mięśni krtani poprzez odzwierciedlenie pobudzenia nerwowego badanego mięśnia. Na rozwój metody szczególny wpływ miały prace Faaborg-Anderson [4], opisujące aktywności mięśni krtani podczas zadań fonacyjnych i niefonacyjnych, oraz prace Hirano i Buchthal nad morfologią jednostek ruchowych mięśni krtani [5].
\end{abstract}

Niniejsza praca ma na celu przegląd literatury światowej na temat współczesnego wykorzystywania badania elektromiograficznego w otolaryngologii i foniatrii.

LEMG daje możliwość dokładnej oceny czynności fałdów głosowych oraz gardła, co znajduje zastosowanie głównie w diagnostyce porażeń fałdów głosowych - zaburzeń w zakresie unerwienia ruchowego i czuciowego, dysfagii, oraz w pracach klinicznych nad sposobami tworzenia głosu [6]. Varadarajan i współautorzy wyszczególnili 4 najistotniejsze zastosowania elektromiografii krtani:

1) diagnostyka, ocena stopnia zaawansowania i prognostyka zaburzeń ruchu fałdów głosowych,

2) lokalizacja miejsca iniekcji przy zabiegach mikrochirurgicznych (takich jak wstrzyknięcie toksyny botulinowej),

3) monitorowanie nerwów krtaniowych podczas zabiegów,

4) ocena mięśni i nerwów w chorobach neurologicznych mogących uszkadzać funkcję krtani (takich jak miastenia gravis, stwardnienie zanikowe boczne, miopatia).

Głównym objawem klinicznym chorób neurolaryngologicznych krtani, spotykanym w praktyce otolaryngologicznej 
Tabela 1. Mięśnie wewnętrzne krtani, ich funkcja, unerwienie oraz objawy porażenia. Tabela stworzona przez autorki na podstawie informacji zawartych w literaturze $[1,30,31]$

Table 1. Internal muscles of the larynx, their function, innervation and paralysis symptoms. The table was created by the authors on the basis of the literature $[1,30,31]$

\begin{tabular}{|c|c|c|c|}
\hline Mięsień & Funkcja & Unerwienie & Objawy porażenia \\
\hline Pierścienno-tarczowy & napinanie & $\begin{array}{l}\text { Gałąź zewnętrzna nerwu } \\
\text { krtaniowego górnego }\end{array}$ & $\begin{array}{l}\text { Asymetria fali śluzówkowej, spowolnione } \\
\text { ruchy porażonego fałdu głosowego. } \\
\text { Asymetria nalewek (niżej położona po stronie } \\
\text { porażonej). W obustronnym porażeniu } \\
\text { zwieranie występuje tylko z tyłu fałdów }\end{array}$ \\
\hline Tarczowo-nalewkowy & zwieranie & $\begin{array}{l}\text { Gałąź przednia przedniej } \\
\text { (ruchowej) gałęzi nerwu } \\
\text { krtaniowego dolnego }\end{array}$ & Atrofia porażonego fałdu \\
\hline $\begin{array}{l}\text { Pierścienno-nalewkowy } \\
\text { boczny }\end{array}$ & zwieranie & $\begin{array}{l}\text { Gałąź przednia przedniej } \\
\text { (ruchowej) gałęzi nerwu } \\
\text { krtaniowego dolnego }\end{array}$ & Atrofia porażonego fałdu \\
\hline $\begin{array}{l}\text { Pierścienno-nalewkowy } \\
\text { tylny }\end{array}$ & rozwieranie & $\begin{array}{l}\text { Gałąź tylna przedniej } \\
\text { (ruchowej) gałęzi nerwu } \\
\text { krtaniowego dolnego } \\
\text { (u 50\% włókna nerwowe } \\
\text { z dwóch stron) }\end{array}$ & Problem z odwodzeniem fałdu głosowego \\
\hline Międzynalewkowy & zwieranie & $\begin{array}{l}\text { Gałąź tylna nerwu } \\
\text { krtaniowego dolnego włókna } \\
\text { nerwowe z dwóch stron }\end{array}$ & Atrofia porażonego fałdu \\
\hline
\end{tabular}

i foniatrycznej, jest zaburzenie ruchu fałdu głosowego (porażenie, niedowład). W tych sytuacjach, oprócz szczegółowo zebranego wywiadu, oceny głosu i badania laryngostroboskopowego, LEMG powinno być podstawowym elementem diagnostyki [7]. Jak podkreśla Gavazzoni ze współautorami, badanie to ma szczególne znaczenie $\mathrm{w}$ diagnozie i wyborze postępowania terapeutycznego u osób z porażeniem nerwów krtaniowych [8]. Nieprawidłowa czynność elektryczna mięśnia pozwala na potwierdzenie niedowładu lub porażenia fałdu głosowego, podczas gdy prawidłowy zapis LEMG przy obserwowanych zaburzeniach ruchu fałdu głosowego sugeruje unieruchomienie nalewki w stawie pierścienno-nalewkowym $[9,10]$. Mięśnie wewnętrzne krtani wykorzystywane $\mathrm{w}$ diagnostyce elektromiograficznej z opisem unerwienia i funkcji przedstawiono w tabeli 1 .

\section{Charakterystyka badania LEMG}

Badanie EMG krtani obrazuje różnicę pomiędzy aktywnością elektryczną badanego mięśnia (próbkowanego igłą) a powierzchnią referencyjną (np. elektrodą na powierzchni skóry szyi). Różnica przedstawiana jest na oscyloskopie bądź ekranie komputerowym oraz przez głośnik. Analiza EMG krtani polega na badaniu 3 typów aktywności elektrycznej: insercyjnej, spontanicznej oraz wolicjonalnej.

Aktywność insercyjna jest to fizjologiczny wzrost aktywności elektrycznej przy przebijaniu igłą błony mięśnia w spoczynku (depolaryzacja włókien). W warunkach fizjologicznych, po aktywności insercyjnej powinna nastąpić cisza elektryczna. Wydłużony > $400 \mathrm{~ms}$ czas aktywności, zbyt słaba lub silna odpowiedź świadczą o patologii.

Stwierdzenie aktywności spontanicznej w badaniu elektromiograficznym zawsze świadczy o patologii. Typ ten obrazuje niestabilność błony mięśniowej w wyniku odnerwienia i utraty pobudzenia neuronalnego. W przypadku braku regeneracji nerwowej, nieprawidłowa aktywność spontaniczna pozostaje aż do atrofii mięśnia. Aktywność spontaniczna oznacza odnerwienie mięśnia, jednak może być również stwierdzana $\mathrm{w}$ miopatiach.

Aktywność wolicjonalną definiuje się jako wystąpienie potencjałów jednostek ruchowych podczas wykonywania odpowiedniego zadania. W tego typu aktywności oceniana jest morfologia potencjałów czynnościowych jednostek ruchowych osoby badanej. W ocenie brane są pod uwagę: faza, amplituda, czas trwania oraz poziom rekrutacji jednostek. Czas trwania i amplituda są proporcjonalne do liczby włókien mięśniowych w każdej jednostce ruchowej. Każdy mięsień charakteryzuje się określoną liczbą włókien. W przypadku krtani ich liczba waha się od 5 do 10.

Unikalność LEMG w stosunku do EMG innych mięśni wynika z charakterystyki mięśni krtani. Są one małe, usytuowane blisko siebie i niepalpacyjne, co stanowi trudność przy konieczności precyzyjnego nakłucia. Prawidłowe usytuowanie elektrody może dodatkowo utrudniać nieprawidłowa aktywność elektryczna mięśni, spowodowana zjawiskiem reinnerwacji przy ruchach paradoksalnych. Mięśnie krtani są cyklicznie słabo pobudzane przez fazy oddechowe, dlatego trudno jest ocenić ich aktywność insercyjną i spontaniczną. W ocenie aktywności wolicjonalnej, oprócz fonacji, poleca się wąchanie i przełykanie. U pacjentów z zaawansowanymi chorobami neurologicznymi stwierdzane są trudności przy dłuższym utrzymywaniu napięcia mięśni krtani, co uniemożliwia ocenę tego typu aktywności.

W tabeli 2. przedstawiono techniki nakłuwania wybranych mięśni wewnętrznych krtani.

Możliwe powikłania badania związane są z koniecznością nakłucia badanego mięśnia. Należą do nich: krwawienie, 
Tabela 2. Techniki nakłucia w badaniu elektromiograficznym krtani. Tabela stworzona przez autorki na podstawie informacji zawartych w literaturze [1]

Table 2. Insertion techniques for laryngeal electromyography. The table was created by the authors on the basis of the literature [1]

\begin{tabular}{|c|c|c|}
\hline Mięsień & Położenie elektrody & $\begin{array}{c}\text { Weryfikacja poprawnego umiejscowienia } \\
\text { elektrody }\end{array}$ \\
\hline Pierścienno-tarczowy & $\begin{array}{l}\text { Nakłucie } 5 \text { mm bocznie od linii pośrodkowej, } \\
\text { na poziomie dolnej krawędzi chrząstki } \\
\text { pierścieniowatej. Igłę kieruje się na róg dolny } \\
\text { chrząstki tarczowatej }\end{array}$ & $\begin{array}{l}\text { Glissando, brak aktywności podczas } \\
\text { podnoszenia głowy }\end{array}$ \\
\hline Tarczowo-nalewkowy & $\begin{array}{l}\text { Nakłuwany w linii lub lekko bocznie od linii } \\
\text { pośrodkowej szyi, na poziomie błony pierścienno- } \\
\text { tarczowej. lgłę kieruje się bocznie i w górę, } \\
\text { w kierunku rogu górnego chrząstki tarczowatej }\end{array}$ & $\begin{array}{l}\text { Uzyskanie aktywności elektrycznej przy } \\
\text { fonacji, natomiast aktywności nie stwierdza } \\
\text { się podczas wąchania lub podnoszenia głowy }\end{array}$ \\
\hline $\begin{array}{l}\text { Pierścienno-nalewkowy } \\
\text { boczny }\end{array}$ & $\begin{array}{l}\text { Nakłuwany 7-8 mm bocznie od linii pośrodkowej } \\
\text { na poziomie błony pierścienno-tarczowej. Igłę } \\
\text { kieruje się bocznie i w górę, w kierunku rogu } \\
\text { górnego chrząstki tarczowatej }\end{array}$ & $\begin{array}{l}\text { Uzyskanie aktywności elektrycznej przy } \\
\text { fonacji, natomiast aktywności nie stwierdza } \\
\text { się podczas wąchania lub podnoszenia głowy }\end{array}$ \\
\hline $\begin{array}{l}\text { Pierścienno-nalewkowy } \\
\text { tylny }\end{array}$ & $\begin{array}{l}\text { Nakłuwany w linii pośrodkowej szyi, na poziomie } \\
\text { błony pierścienno-tarczowej. Igła przechodzi przez } \\
\text { przestrzeń podgłośniową i następnie tylną blaszkę } \\
\text { chrząstki pierścieniowatej. } \\
\text { Jeżeli pacjent jest odprężony, możliwy jest drugi } \\
\text { wariant, podczas którego badacz rotuje krtań } \\
\text { w celu lepszej palpacji chrząstki pierścieniowatej }\end{array}$ & $\begin{array}{l}\text { Uzyskanie aktywności elektrycznej przy } \\
\text { wąchaniu, brak aktywności podczas fonacji }\end{array}$ \\
\hline Międzynalewkowy & $\begin{array}{l}\text { Nakłuwany pod kontrolą endoskopu, igła } \\
\text { przechodzi przezgłośniowo, przeszywając mięsień } \\
\text { międzynalewkowy dolny w linii pośrodkowej, } \\
\text { pomiędzy nalewkami }\end{array}$ & Uzyskanie aktywności elektrycznej przy fonacji \\
\hline
\end{tabular}

zakażenie miejscowe i przejściowe zaburzenia głosu związane $\mathrm{z}$ obecnością igły w mięśniu. Możliwe jest znieczulenie miejscowe przy silnym odruchu kaszlowym.

Przeciwskazaniem do wykonania badania są zmiany na skórze nad krtanią oraz ostre zapalenie krtani [3].

\section{Zastosowanie kliniczne LEMG}

W badaniu elektromiograficznym krtani za pozytywny czynnik prognostyczny uznaje się zachowanie morfologii potencjału jednostki motorycznej z energiczną rekrutacją. Stwierdzenie natomiast aktywności spontanicznej, zmienionej morfologii potencjału jednostki ruchowej, zmniejszonej rekrutacji czy tak zwanej ciszy elektrycznej stanowi negatywny czynnik prognostyczny. Aktywność elektryczna mięśni krtani bardzo rzadko powraca po 3 miesiącach braku potencjałów jednostek ruchowych. W przypadku braku poprawy wyników LEMG w badaniach wykonywanych w odstępie 6 tygodni, prawdopodobieństwo powrotu czynności fałdu głosowego jest niewielkie [3].

Opisywany w literaturze umiarkowany odsetek wyzdrowień po idiopatycznych porażeniach fałdów głosowych wskazuje na zdolność do regeneracji nerwów krtaniowych [11]. Zakres wartości prognostycznej badania LEMG przy jednostronnym porażeniu fałdu głosowego w różnych publikacjach wynosi od ponad $60 \%$ do $89 \%$ [12-14]. Badanie jest również wykorzystywane $\mathrm{w}$ diagnostyce i prognostyce obustronnego porażenia fałdów głosowych $[15,16]$. Odczuwana przez pacjentów w powyższych sytuacjach duszność często wymaga interwencji chirurgicznej. LEMG ma w tych sytuacjach szczególną wartość, gdyż pomaga w wyborze czasu i metody interwencji oraz strony operowanej. Decyzja o wyborze metody odnosi się do zabiegu tracheotomii lub zabiegów poszerzających szparę głośni, takich jak laterofiksacja fałdu głosowego, chordektomia tylna, arytenoidektomia częściowa lub całkowita. $Z$ badań nad powrotem aktywności mięśni krtani u osób z obustronnym porażeniem fałdów głosowych po operacjach tarczycy [15] wynika, iż decyzja o zastosowaniu zabiegu poszerzającego szparę głośni powinna być podjęta po dziewięciomiesięcznej obserwacji. W wyjątkowych sytuacjach można podjąć decyzję o wcześniejszym wykonaniu zabiegu - wtedy, gdy pacjent nie wyrazi zgody na tracheostomę.

Badanie LEMG jest również pomocniczo wykorzystywane $\mathrm{w}$ diagnostyce po celowych uszkodzeniach jatrogennych nerwów krtaniowych [17]. Opisywany w LEMG częściowy powrót aktywności mięśni podczas fonacji, mimo stwierdzanego w badaniu porażenia fałdu głosowego u pacjentów po przecięciu nerwu krtaniowego wstecznego z powodu dysfonii spastycznej, sugerował regenerację włókien nerwowych. U tych pacjentów konieczne było dodatkowe zastosowanie toksyny botulinowej typu A w celu zmniejszenia uciążliwych objawów choroby [17].

Wspomniane zjawisko reinnerwacji, w przypadku połączenia kilku rozgałęzień jednego aksonu z włóknami ruchowymi skierowanymi do przeciwstawnych mięśni, powoduje ruchomość paradoksalną i - jak wspomniano - utrudnia prawidłowe umiejscowienie elektrody w mięśniu. Zjawisko to ma miejsce ze względu na przebieg nerwu krtaniowego wstecznego zarówno do mięśni zwierających, jak i rozwierających fałdy głosowe. Przydatną opcją w diagnostyce 
ruchomości paradoksalnej i dystonii jest wielokanałowe cienkoigłowe EMG, które zapewnia jednoczasowy obraz z wielu mięśni krtani.

Podczas przeprowadzania EMG w celu oceny czynności ruchowej krtani zbadać można wszystkie najistotniejsze mięśnie krtani (pierścienno-tarczowy, tarczowo-nalewkowy, pierścienno-nalewkowy boczny oraz tylny, międzynalewkowy). Zastosowanie znajdują tu elektrody igłowe, drutowe-haczykowate i powierzchniowe $[18,19]$. Najpowszechniej stosowany jest przezskórny dostęp do mięśni, za pomocą igieł bipolarnych. Najczęściej badanym mięśniem jest mięsień tarczowo-nalewkowy. Oprócz klasycznych dostępów opisanych w tabeli 2., możliwe jest zastosowanie innych technik dostępu. Do mięśnia tarczowo-nalewkowego możliwy jest dostęp przez jamę ustną, pod kontrolą endoskopii i przy użyciu aplikatora zawierającego elektrodę drutową haczykową. Monitorowanie unerwienia mięśni krtani z zakresu nerwu krtaniowego wstecznego jest możliwe również za pomocą elektrody wprowadzonej na rurce dotchawiczej. $Z$ metody tej można korzystać podczas procedur chirurgicznych, przy których istnieje ryzyko uszkodzenia unerwienia krtani [20]. Wysokie ryzyko uszkodzenia nerwów krtani jest spowodowane ich długim przebiegiem w szyi i klatce piersiowej. Nerwy krtaniowe są usytuowane $\mathrm{w}$ pobliżu wielu istotnych życiowo struktur i łatwo mogą ulec uszkodzeniu podczas zabiegów chirurgicznych przeprowadzanych zarówno w obrębie szyi, jak i klatki piersiowej. Stopień i rozległość ich uszkodzenia może być zmienny [16] i ma wpływ na szanse powrotu funkcji unerwianych struktur [21]. W różnicowaniu miejsca i strony porażenia za pomocą LEMG możliwe jest oznaczenie pojedynczych obwodowych uszkodzeń lub wysokiego uszkodzenia nerwu błędnego. Porównanie wyników badania mięśni pierścienno-tarczowych i tarczowo-nalewkowych pozwala określić stronę uszkodzenia. W przypadku nieprawidłowości stwierdzanych obustronnie, konieczna jest diagnostyka podstawy czaszki i ośrodkowego układu nerwowego. Stwierdzenie nieprawidłowości LEMG jedynie w badaniu mięśnia tarczowo-nalewkowego może wskazywać na patologię w obrębie nerwu krtaniowego dolnego i potrzebę wykonania diagnostyki obrazowej szyi i śródpiersia. W przypadku izolowanego porażenia nerwu krtaniowego górnego, gdzie występują niespecyficzne objawy wokalne i zaburzenia sensoryczne krtani, jedynie badanie LEMG daje możliwość postawienia diagnozy.

Prace nad rozpowszechnieniem metody LEMG przyczyniły się do poszukiwań mniej inwazyjnych metod badania aktywności mięśni krtani. Próby wprowadzenia badania wykorzystującego jedynie elektrody naklejane na powierzchnię skóry zakończyły się niepowodzeniem ze względu na zbyt małą wiarygodność i powtarzalność badania [22].

W przypadku jednostek chorobowych, w przebiegu których występuje drżenie głosu, badanie LEMG posiada szczególną wartość diagnostyczną. Badanie pozwala w sposób bezpośredni ocenić czynność poszczególnych mięśni oraz interakcje pomiędzy nimi [17]. Ze względu na różnice w wynikach, możliwe jest przeprowadzenie diagnostyki różnicowej u pacjentów z drżeniem samoistnym, dysfonią spastyczną, zespołem Tourette’a czy tikami głosowymi $[23,24]$. Nieprawidłowości we wzajemnej czynności mięśni odwodzących i przywodzących fałdów głosowych podczas zadań fonacyjnych wykryto za pomocą badań LEMG również u pacjentów z niepłynnością mowy [25]. W praktyce klinicznej, spośród wyżej wymienionych chorób, LEMG znajduje najistotniejsze zastosowanie w dysfonii spastycznej. Współcześnie uważa się, iż choroba ta ma podłoże heterogenne - neurologiczne z komponentą psychogenną [26,27]. Klinicznie charakteryzuje się skrajnie partą i chrapliwą fonacją, $\mathrm{z}$ drżeniem i nieregularnym załamywaniem się głosu [28]. W leczeniu dysfonii spastycznej stosuje się iniekcje toksyny botulinowej, której neurotoksyczne działanie polega na blokowaniu przewodzenia impulsów do mięśni. Iniekcji dokonuje się pod kontrolą LEMG do mięśni tarczowo-nalewkowych (w przypadku dysfonii spastycznej addukcyjnej), lub mięśni pierścienno-nalewkowych tylnych (w przypadku dysfonii spastycznej abdukcyjnej).

Jak wynika z powyższych przykładów, LEMG jest jedynym badaniem pozwalającym na zróżnicowanie wielu schorzeń narządu głosu i mowy. Według konsensusu Europejskiego Stowarzyszenia Laryngologicznego (European Laryngological Society) z 2012 roku, badanie elektromiograficzne krtani powinno stać się standardem diagnostycznym nie tylko neurologów, lecz także otolaryngologów i foniatrów [29].

Przegląd literatury pokazuje, że LEMG jest cennym narzędziem diagnostycznym w ocenie zaburzeń głosu w chorobach neurolaryngologicznych. W nowoczesnej diagnostyce elektromiografia krtani powinna być zatem standardowym elementem procedury diagnostycznej czynnościowych zaburzeń głosu i mowy. Zarówno dane literaturowe, jak i doświadczenia własne wskazują bowiem na dużą przydatność kliniczną badania w ocenie szeroko rozumianej komunikacji międzyludzkiej.

\section{Piśmiennictwo:}

1. Blitzer A, Brin M, Ramig L. Neurologic disorders of the larynx. Second edition. New York: Thieme; 2009.

2. Weddell G, Feinstein B, Paattle R. The electrical activity of voluntary muscle in man under normal and pathological conditions. Brain, 1944; 67: 178-242.

3. Golseth JG. Diagnostic contributions of the electromyogram. Calif Med, 1950; 73: 355-57

4. Faaborg-Anderson K. Electromyographic investigation of intrinsic laryngeal muscles in humans. Acta Physiol Scand, 1957; 41(Suppl. 140): 1-149.
5. Buchthal F. Electromyography of intrinsic laryngeal muscles. QJ Exp Physiol Cogn Med Sci, 1959; 44: 137-48.

6. Varadarajan V, Blumin JH, Bock JM. State of the art of laryngeal electromyography. Current Otorhinolaryngology Reports, 2013; 171-77.

7. Fang T, Pei Y, Hsin L, Lin W, Lee L, Li H i wsp. Quantitative laryngeal electromyography assessment of cricothyroid function in patients with unilateral vocal fold paralysis. Laryngoscope, 2015; 125(11): 2530-35. 
8. Gavazzoni FB, Scola RH, Lorenzoni PJ, Kay CS, Werneck LC. The clinical value of laryngeal electromyography in laryngeal immobility J Clin Neurosci, 2011; 18(4): 524-27.

9. Koufman JA, Postma GN, Whang CS, Rees CJ, Amin MR, Belafsky PC i wsp. Diagnostic laryngeal electromyography: The Wake Forest experience 1995-1999. Otolaryngol Head Neck Surg, 2001; 124: 603-6.

10. Rontal E, Rontal M, Silverman B, Kileny PR. The clinical differentiation between vocal cord paralysis and vocal cord fixation using electromyography. Laryngoscope, 1993; 103: 133-37.

11. Munin MC, Rosen CA, Zullo T. Utility of laryngeal electromyography in predicting recovery after vocal fold paralysis. Arch Phys Med Rehabil, 2003; 84(8): 1150-53.

12. Wang CC, Chang MH, Virgilio A, Jiang R, Lai H, Wang CP i wsp. Laryngeal electromyography and prognosis of unilateral vocal fold paralysis - A long-term prospective study. Laryngoscope, 2015; 125(4): 898-903.

13. Mostafa BE, Gadallah NA, Nassar NM, Al Ibiary HM, Fahmy HA, Fouda NM. The role of laryngeal electromyography in vocal fold immobility. J Othorhinolaryngol Relat Spec, 2004; 66(1): 5-10.

14. Eckel HE, Thumfart M, Wassermann K, Vossing M, Thaumfart WF. Cordectomy versus arytenoidectomy in the management of bilateral vocal cord paralysis. Ann Otol Rhinol Laryngol, 1994; 103: 852-57.

15. Schneider W, Wolf S, Krause J. Electromyographische Untersuchung und Verlaufsbeobachtung von beidseitigen Rekurrensparesen nach Schilddrusenoperationen. HNO, 1997; 45: 551-55.

16. Sulica L, Cultrara A, Blitzer A. Vocal fold paralysis: Causes, outcomes and clinical aspects. W: Sulica L, Blitzer A, red. Vocal Fold Paralysis. Berlin, Heidelberg, New York: Springer; 2006, 33-54.

17. Sulica L, Blitzer A, Brin MF, Stewart CF. Botulinum Toxin management of adductor spasmodic dysphonia after failed recurrent laryngeal nerve section. Ann Otol Rhinol Laryngol, 2003; 112: 499-505.

18. Wiskirska-Woźnica B. Możliwości obiektywizacji badania foniatrycznego w zaburzeniach mowy. Otorynolaryngologia 2014; 13(3): 127-30.
19. Koivu M. Multi-Motor Unit Potential Analysis and Other Quantitative Techniques for Laryngeal Electromyogram. Journal of Clinical Neurophysiology, 2015; 32(4): 309-13.

20. Atlas G, Lee $\mathrm{M}$. The neural integrity monitor electromyogram tracheal tube: Anesthetic considerations. J Anaesthesiol Clin Pharmacol, 2013; 29(3): 403-4.

21. Arviso L, Johns M, Mathison C, Klein A. Long-term outcomes of injection laryngoplasty in patients with potentially recoverable vocal fold paralysis. Laryngoscope, 2010; 120: 2237-40.

22. Remacle M, Eckel HE, red. Surgery of larynx and trachea. Berlin, Heidelberg: Springer - Verlag; 2010, 257-68.

23. Maronian NC, Waugh P, Robinson L, Hillel AD. Tremor laryngeal dystonia: Treatment of the lateralcricoarytenoid muscle. Ann Otol Rhinol Laryngol, 2004; 113: 349-55.

24. Kimaid PA, Quagliato EM, Crespo AN, Wolf A, Viana MA, Resende LA. Laryngeal electromyography in movement disorders: preliminary data. Arq Neuropsiquiatr, 2004; 62: 741-44.

25. Freeman FJ, Ushijiama T. Laryngeal muscle activity during stuttering. J Speech Hear Res, 1978; 21: 538-62.

26. Morawska J, Niebudek-Bogusz E. Dysfonia spastyczna - opis przypadku i przegląd piśmiennictwa. Otorynolaryngologia, 2014; 13(3): 169-75.

27. Miaśkiewicz B, Szkiełkowska A, Ratyńska J, Skoczylas A, Skarżyński H. Objawy foniatryczno-laryngologiczne w chorobie neuronu ruchowego. Otolaryngologia Polska, 2010; 64: 171-76.

28. Szkiełkowska A, Miaśkiewicz B, Baczyńska-Świerczyńska S, Szymańska E. Trudności terapeutyczne w dysfonii spastycznej - opis przypadku. Polski Merkuriusz Lekarski, 2006; XX, 119: 557-59.

29. Volk G, Hagen R, Pototschnig C, Friedrich G, Nawka T, Arens C i wsp. Laryngeal electromyography: a proposal for guidelines of the European Laryngological Society. European Archives of Oto-Rhino-Laryngology, 2012; 269(10): 2227-45.

30. Bochenek A, Reicher M. Anatomia człowieka. Wydanie XII. Warszawa: Wydawnictwo Lekarskie PZWL; 2010.

31. Obrębowski A. Narząd głosu i jego znaczenie w komunikacji społecznej. Wydawnictwo Naukowe Uniwersytetu Medycznego im. Karola Marcinkowskiego; 2008: 96. 